International Journal of Current Advanced Research

ISSN: O: 2319-6475, ISSN: P: 2319 - 6505, Impact Factor: SJIF: 5.995

Available Online at www.journalijcar.org

Volume 6; Issue 5; May 2017; Page No. 3610-3612

DOI: http://dx.doi.org/10.24327/ijcar.2017.3612.0330

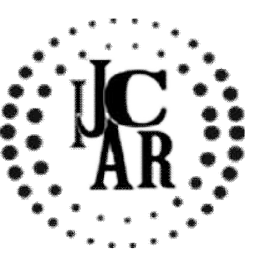

Research Article

\title{
PERCUTANEOUS NEPHROLITHOTOMY COMPLICATIONS: OUR EXPERIENCE WITH 100 CASES
}

\author{
Arun Vijaiyan., Saravanan., Jayaganesh and Ezhil Sundar
}

Department of Urology, Government Royapettah Hospital and Government kilpauk Medical College, Chennai, India

\section{A R T I C L E I N F O}

\section{Article History:}

Received $7^{\text {th }}$ February, 2017

Received in revised form $12^{\text {th }}$ March, 2017

Accepted $15^{\text {th }}$ April, 2017

Published online $28^{\text {th }}$ May, 2017

\section{Key words:}

Nephrolithotomy, Collecting System Injury

\begin{abstract}
A B S T R A C T
We report the outcomes of 100 percutaneous nephrolithotomy (PCNL) procedures performed in our institution between august 2015 and december 2016. The PCNL procedures were performed under general anaesthesia. The ureteral catheter was installed in the supine position during cystoscopy under C-arm fluoroscopy guidance and, after turning the patient into the prone position, the kidney with stone was entered with a two part metal needle under flouoroscopy. The Amplatz renal dilator set was used. Stones were fragmented with pneumatic lithotripter. After retrieval of stone fragments the nephrostomy tube was placed in the nephroscope sheath. After completion of PCNL procedures, residual asymptomatic stones of $4 \mathrm{~mm}$ or less in size were considered clinically insignificant. Of the total number of patients, $89(89 \%)$ achieved stone clearance. Bleeding requiring transfusion occurred in 16 cases $(16 \%)$, of which $1(1 \%)$ was treated with embolisation angiography. A double-J stent was inserted in 92 patients $(92 \%)$.No pneumothorax or colon perforation was reported. In angiography, the bleeding site identified to be pseudoaneurysm and selective angioembolisation was performed.
\end{abstract}

Copyright $₫ 2017$ Arun Vijaiyan et al. This is an open access article distributed under the Creative Commons Attribution License, which permits unrestricted use, distribution, and reproduction in any medium, provided the original work is properly cited.

\section{INTRODUCTION}

The incidence of urolithiasis varies according to age and geographical region, and is of particular concern in developing countries. With the introduction of percutaneous nephrolithotomy (PCNL) in 1976, open surgical approaches have begun to lose their popularity in the treatment of urolithiasis $^{1}$. Although PCNL has been accepted as a minimally invasive treatment modality, the technique can lead to possible complications, including bleeding and injury to the collection system ${ }^{2}$. The challenge with percutaneous surgery, then, is to do so while also avoiding complications. If complications do occur, then prompt recognition and management will usually avoid major morbidity.In this retrospective study we report our experience with PCNL and evaluate the clinical outcomes, including morbidity and mortality.

\section{MATERIALS AND METHODS}

This retrospective study was conducted in a single urology clinic and reviewed the medical date of 100 patients up to the age of 80 years who underwent PCNL between August 2015

*Corresponding author: Arun Vijaiyan

Department of Urology, Government Royapettah Hospital and Government and December 2016. Preoperative patient histories, physical examinations, and routine laboratory tests including blood biochemistry, urinalysis, and urine cultures were evaluated. An abdominopelvic ultrasound, plain abdominal films, and intravenous urography were used as diagnostic imaging tools to determine stone size, location, and anatomical clues, as well as for planning treatment. Computed tomography was used in patients suspected of having renal abnormalities, allergies to the contrast medium, and the presence of a retrorenal colon, and also in patients with a non-opaque stone. Patients with sterile urine underwent PCNL with antibiotic prophylaxis. Patients with urinary infections were operated on following treatment with an antibiotic prescribed after urine culture and sensitivity tests.

After the placement of ureteral catheter via cystoscopy in the lithotomy position under general anesthesia, the patient was placed in a prone position. PCNL access was gained using an 18-G needle and a guide wire passed from inside, under biplanar fluoroscopic guidance. Using Amplatz dilators, the percutaneous tract was dilated up to $30 \mathrm{Fr}$ for the $24 \mathrm{Fr}$ nephroscope (Karl Storz, Germany).Following the breakage of the stones using a pneumatic lithotripter (Swiss LithoClast $\AA$ ), a 14-22 Fr Nephrostomy tube or Foley catheter was placed into the renal tract. On the sw postoperative day, plain abdominopelvic radiography and antegrade pyelography (if needed) were used to assess stone clearance and to detect 
and pathology of the pelvicalyceal system that occurred during surgery. Stone pieces that appeared smaller than $4 \mathrm{~mm}$ on plain X-ray were accepted as clinically insignificant residual fragments. Stone burden and location, number, size and location of the renal tract, types of instruments, complications, stone clearance, duration of nephrostomy, and hospitalization time were recorded as pre and postoperative factors. Patients with missing data were excluded from the study.

\section{RESULTS}

Of the 100 cases, we achieved complete stone clearance in 89(89\%). When complications were evaluated: bleeding requiring transfusion occurred in 12 patients $(12 \%)$, of which 1 case $(1 \%)$ required angioembolisation, Urinary extravasation occurred in 11 cases $(11 \%)$ and urinoma formation in 4 cases (4\%); Pneumothorax or colon perforation occurred in none. Post operative fever occurred in 16 cases $(16 \%)$ and 7 cases $(7 \%)$ went in to sepsis. 8 cases in the study required a second stage percutaneous nephrolithotomy due to increased stone burden. No neuromusculoskeletal complications or venous thromboembolism occurred in the study. No mortality occurred in the current study.(Table .1.)

Table.1

\begin{tabular}{cc}
\hline COMPLICATION & FREQUENCY, n.(\%) \\
\hline Haemorrhage: & $22(22 \%)$ \\
Requiring transfusion: & $1(1 \%)$ \\
Angioembolisation: & \\
Collecting system injury: & $13(11 \%)$ \\
Urinary extravasation: & $4(4 \%)$ \\
Urinoma: & $16(16 \%)$ \\
Postoperative fever & $7(7 \%)$ \\
Sepsis & 0 \\
Pleural injury & 0 \\
Visceral injury & 0 \\
Neuromuscular complications & 0 \\
Venous embolism & 0 \\
Death &
\end{tabular}

\section{DISCUSSION}

Currently, open surgery is rarely performed in the management of kidney stones, and PCNL has become a frequently applied minimally invasive surgery that leads to fewer complications, shorter durations of hospital stay, and reduced scar tissue formation. ${ }^{3,4}$. The success rate of PCNL procedures has been reported as $72-98 \%$ in a large series published in the literature. ${ }^{5-7}$ Sugura et al. ${ }^{8}$ reported a $98 \%$ success rate in a total of 1,000 patients who underwent PCNL in 1985, which is one of the first larger published series. The success rate in our series was $89 \%$ in a total of 100 cases.

PCNL, as a minimally invasive surgical method for the treatment of renal stones, can lead to complications including bleeding requiring transfusion, lung injury, bowel injury, major vascular injury, and sepsis. Fever and bleeding were the most frequently reported complications.

\section{Haemorrhage}

The overall complication rate in the present study was $12.3 \%$, with haemorrhage being the most common complication. In our series, factors associated with hemorrhage include patient characteristics, multiple access sites, increasing tract size, prolonged operative time, and renal pelvic perforation.During the PCNL procedure, one of the most important complications is the development of acute haemorrhage. The transfusion rate has been reported to be $6 \%$ to $20 \%$. In the current study acute haemorrage requiring transfusion occurred in $21 \%$ of cases. Development of arteriovenous fistulaor pseudoaneurysm can cause delayed haemorrhage, with a rate of 5\%. Any report ofbright red blood in the urine after percutaneous renalsurgery should prompt hospital admission and considerationof angiography, which is diagnostic in morethan $90 \%$ of cases.In our series, the rate of bleeding requiring transfusion $(12 \%)$ was in accordance with the published literature. One case had significant delayed haemorrhagefound to be a pseudoaneurysm for which selective angioembolisation using coil was performed.

\section{Collecting system injury}

Tears in the infundibulum are not uncommon during percutaneoussurgery of the upper urinary tract collecting systemRenal pelvic perforation is usually recognized intraoperatively. Collapse of a previously distended renal pelvis is a usual sign if the perforation. Lee at al. ${ }^{15}$ reported renal pelvis laceration $(0.9 \%)$, ureteral avulsion $(0.2 \%)$, and urinoma formation $(0.3 \%)$ in their series. In our series, we observed urinary extravasation in $11 \%$ of cases and urinoma formation in $4 \%$ of cases which resolved with double-J stent insertion.

\section{Visceral injury}

Injuries to the neighbouring organs including liver, spleen, colon, and small intestine can also occur.. Studies based on CT and MRI have suggested thatsplenic and hepatic injuries should be unlikely unlessthe kidney is accessed above the 10 th rib.Visceral injury occurred in none of the cases in the study

\section{Pleural injury}

Supra and intercostal access might be related with occurrence of lung injury and pneumothorax. In the literature, the rates of hydrothorax and pneumothorax after PCNL were reported to the $6-12 \% .{ }^{13}$ Palnizky et $a l .{ }^{14}$ reported and $8 \%$ rate of pulmonary complications in their experience. In our series, pulmonary complications occurred in none of the cases as supracostal access was not required in any of the patients.

\section{Postoperative fever and sepsis}

After percutaneous nephrolithotomy, $15 \%$ to $30 \%$ ofpatients have a fever (Charton et al, 1986; Troxel and Low, 2002; Aghdas et al, 2006). Most patients with fever after percutaneous nephrolithotomy, assuming appropriate antimicrobialprophylaxis, do not have infection (Cadeddu et al, 1998). Sepsis occurs in $1 \%$ to $2 \%$ of patients after perecutaneousnephrolithotomy. (Dogan et al, 2007; Gonen et $a l, 2008 \mathrm{~b}$ ). In the current study, Postoperative fever occurred in $16 \%$ and $7 \%$ went in to sepsis.

\section{CONCLUSION}

In our experience, PCNL, is a generally safe and effective minimally invasive surgical modality with acceptable complications and short durations of hospital stay when used for treating kidney stones. 


\section{References}

1. FernströmI, Johansson B. Percutaneous pyelolithotomy. A new extraction technique. Scand $J$ Urol Nephrol.1976; 10(3):257-9.

2. Woodside $\mathrm{J} \mathrm{R}$ et al. Percutaneous stone removal in children. J Urol.1985; 134(6):1166-7.

3. AntonelliJA, PearleMS. Advances in percutaneou snephrolithotomy. Urol Clin North Am. 2013; 40(1):99113.

4. Hasun $\mathrm{R}$ et al. Percutaneous coagulum nephrolithotripsy: a new approach. $B r J$ Urol.1985; 57(6):605-9.

5. Goldwasser B et al. Factors effecting the success rate of percutaneous nephrolithotripsy and the incidence of retained fragments. J Urol.1986; 136(2):358-60.

6. Michaels $\mathrm{E} \mathrm{K}$ et al. Bacteriuria following extra corporeal shock wave lithotripsy of infection stones. JUrol.1988; 140(2):254-6.

7. Segura J W et al. Nephrolithiasis Clinical Guidelines Panel summary report on the management of staghorncalculi. The American Urological Association Nephrolithiasis Clinical Guidelines Panel. J Urol.1994; 151(6):1648-51.

8. Celik $\mathrm{H}$ et al. An overview of percutaneous nephrolithotomy. EM J Urol.2015;3(1):46-52.
9. Labate $\mathrm{G}$ et al. The percutaneous nephrolithotomy global study: classification of complications. $J$ Endourol.2011; 25(8):1275-80.

10. First Prize (tie): Hemorrhage following percutaneous renal surgery: characterization of an geographic findings $J$ Endourol.2008; 22(6):1129-35.

11. Clayman R V et al, "Endourology of the upper urinary tract: percutaneous renal and ureteral procedures", Walsh P C et al (eds.), Campbell's Urology $7^{\text {th }}$ Edition (1998), Philadelphia, PA: WB Saunders, pp.2789-874.

12. Palnizky $G$ et al. Pulmonary complications following percutaneous nephrolithotomy: a prospective study. CurrUrol.2013; 7(3):113-6.

13. Lee WJ et al. Complications of percutaneous nephrolithotomy. AJR Am J Roentgenol.1987; 148(1):177-80.

14. Mousavi-Bahar S $\mathrm{H}$ et al. Percutaneous nephrolithotomy complications in 671 consecutive patients a single-center experience. Urol J. 2011; 8(4):271-6.

15. Lang EK. Percutaneous nephrostolithotomy and lithotripsy: a multi_institutional survey of complications. Radiology. 1987; 162(1PT1):25-30.

\section{How to cite this article:}

Arun Vijaiyan et al (2017) ' Percutaneous Nephrolithotomy Complications: Our Experience With 100 Cases', International Journal of Current Advanced Research, 06(05), pp. 3610-3612.

DOI: http://dx.doi.org/10.24327/ijcar.2017.3612.0330 